\title{
Expression of intercellular adhesion molecule 1 (ICAM-1, CD54) in colonic epithelial cells
}

I Medizinische Klinik und Poliklinik, JohannesGutenberg-Universität, Mainz, Germany W Dippold B Wittig

W Schwaeble

W Mayet

K-H Meyer zum Büschenfelde

Correspondence to:

Professor Dr W Dippold,

I Medizinische Klinik,

Johannes-Gutenberg-

Jniversität,

Langenbeckstraße 1, D-6500

Mainz, Germany.

Accepted for publication

26 March 1993

\author{
W Dippold, B Wittig, W Schwaeble, W Mayet, K-H Meyer zum Büschenfelde
}

\begin{abstract}
The expression of intercellular adhesion molecule-1 (ICAM-1, CD54) was examined in 16 surgically removed colonic tumours and two colonic carcinoma cell lines. Immunohistochemistry showed a varying percentage of ICAM-1 positive colonic carcinoma cells in 9/16 tissue specimens, while normal colonic tissue (apart from a slight reactivity of endothelial cells) was not stained. The presence of the ICAM-1 molecule on the cell surface and the expression of ICAM-1 mRNA were investigated for two colonic carcinoma cell lines. It was possible to enhance the expression of ICAM-1 considerably by incubating the cells in the presence of inflammatory cytokines in HT-29 and $\mathrm{CaCo}-2$ cells. The responsiveness to either interferon $\alpha$ (IFN- $\alpha)$, tumour necrosis factor $\alpha$ (TNF- $\alpha$ ), or interleukin $1 \beta$ (IL-1 $\beta$ ) treatment was different in each cell line. Interestingly, ICAM-1 is shed by colonic carcinoma cells because soluble sICAM-1 was detected in the cell culture supernatants. In comparison with normal serum samples, the mean value of sICAM-1 in 63 samples of patients with colonic carcinoma and in 20 cases of active inflammatory bowel disease is raised about twofold. It remains to be clarified what part both forms of ICAM-1 play in the course of colonic cancer, ulcerative colitis, and Crohn's disease.

(Gut 1993; 34: 1593-1597)
\end{abstract}

ICAM-1, the intercellular adhesion molecule-1 represents a cell surface bound glycoprotein of 70 to 110 kilodaltons $(\mathrm{kDa})$. It mediates adhesion dependent cell to cell interactions and is expressed on haematopoietic cells such as tissue macrophages, monocytes, B-cells, activated $\mathrm{T}$-cells, germinal centre dendritic cells in tonsils, lymph nodes, and Peyer's patches, as well as on non-haematopoietic cells such as vascular endothelial cells, thymic epithelial cells, certain other epithelial cells, and fibroblasts. ${ }^{1}$ The expression of ICAM-1 and two of its counter receptors, the lymphocyte function associated antigen-1 (LFA-1, CD11a/CD18) and the complement receptor type-3 (CR-3, MAC-1, $\mathrm{CD} 11 \mathrm{~b} / \mathrm{CD} 18$ ) was shown to be essential for most of the lymphocyte/lymphocyte, lymphocyte/phagocyte, and leucocyte/endothelial cell interactions in the immune response. ${ }^{2}$ Moreover, ICAM-1 participates in the transient adhesion of leucocytes to the vascular endothelium and mediates, in part, granulocyte extravasation. Previous reports on fibroblasts and monocytic tumour cell lines, for example, have shown that inflammatory cytokines such as interleukin $1 \beta$ (IL-1 $\beta$ ), tumour necrosis factor $\alpha$ (TNF- $\alpha$ ), and interferon $\gamma$ (INF- $\gamma)$ induce or enhance the expression of ICAM $-1 .^{3}$ In inflammatory bowel disease an increased expression of ICAM-1 on mucosal mononuclear phagocytes on colonic biopsy specimens was shown to be associated with the maintenance of chronic inflammation ${ }^{4}$ and the induction of ICAM-1 expression has been seen on bile duct epithelium, endothelium, and hepatocytes of liver allografts undergoing acute rejection. ${ }^{5}$ In previous reports an expression of ICAM-1 was seen on neoplastic cells of various origins including gastric and pancreatic carcinoma. $^{6-13}$ A considerable expression of ICAM-1 was also seen on fibrous tissue in the vicinity of carcinoma cells and on tumour infiltrating lymphoid cells. ${ }^{14}$ For melanoma, it has been shown that the de novo expression of ICAM-1 correlates with an increased risk of metastasis. ${ }^{10}$

Most recently, a soluble form of the usually membrane bound ICAM-1 molecule was detected in human serum samples. ${ }^{15}$ The cellular source of soluble ICAM-1 (sICAM-1) in samples of healthy blood donors seemed to be from mononuclear cells, because sICAM-1 was only detectable in cell culture supernatants of lymphoid cell lines and peripheral blood mononuclear cell cultures. Raised values of sICAM-1 have been reported in samples of patients with melanoma, ${ }^{16}$ rheumatoid arthritis, systemic lupus erythematosus, metastatic cancer, and acute urolithiasis. ${ }^{17}$

In this study, we show that de novo expression of ICAM-1 occurs in association with colonic carcinoma and that colonic carcinoma cells express both forms of ICAM-1, the usual membrane bound ICAM-1 on their cell surface and the soluble sICAM-1 as detected in the cell culture supernatants of colonic carcinoma cell lines. Enhanced sICAM-1 values were found in serum samples of patients with colonic carcinoma and active inflammatory bowel disease.

\section{Materials and methods}

CELL LINES, MEDIUM, REAGENTS, CYTOKINES, ANTIBODIES, AND SICAM-1 ELISA

The colonic carcinoma cell lines HT-29 and CaCo-2 were donated by Dr L Old, Memorial Sloan-Kettering Cancer Center New York, USA, and Dr Franke, Deutsches Krebsforschungszentrum Heidelberg, Germany.

All cell lines were cultured in CLICK-RPMI 1640 (CMRL) medium containing $10 \%$ basal medium supplement, Seromed (Berlin, Germany). Basal medium supplement is a medium supplement that contains defined amounts of salt, aminoacids, D-glucose, 
vitamins, peptides, and growth factors as described in the company's catalogue. Recombinant IFN- $\gamma$ was supplied by Boehringer (Mannheim, Germany); recombinant IL-1 $\beta$ from Behring (Marburg, Germany), and recombinant TNF- $\alpha$ from Thomae (Biberach, Germany). All three cytokines were expression products purified from recombinant Escherichia coli $(E$ coli $)$ strains. Incubation time and concentration of cytokines were chosen according to optimal responses known for the ICAM-1 upregulation on other tumour cell lines. ${ }^{1718}$ Monoclonal anti-ICAM-1 antibody mAB 7F7 was kindly provided by $\operatorname{Dr} M P$ Dierich (Innsbruck, Austria); as an additional control we used a different anti-ICAM-1 antibody, mAB $84 \mathrm{H} 10$, which was purchased from Dianova (Hamburg, Germany). The sICAM-1 enzyme linked immunosobent assay (ELISA) used to determine sICAM-1 in the cell culture supernatants, in serum samples of healthy blood donors and patients was supplied by Bender Med Systems (Vienna, Austria). Diluted samples as well as undiluted and concentrated cell culture supernatants were assayed according to the protocol enclosed. Monoclonal antibody $\mathrm{mAb}$ $\mathrm{R}-24^{19}$ recognising the ganglioside GD3 on malignant melanoma cells was used as a negative control. Monoclonal antibody mAb W6/32 as positive control reactive with human histocompatibility antigen determinants was purchased from Sera Laboratories (Crawley Down, UK). For immunofluorescence, we used the GAMFITC antibody 6602159 from Coulter Immunology (Hialeah, USA). The tests were performed in LAB-TEK slides as described earlier. ${ }^{20}$

\section{IMMUNOSTAINING OF ICAM-1 ON TISSUES AND}

CELLS

Cryostat sections and cells were tested by indirect immunoperoxidase assays using rabbit anti-mouse antibody P260 Dakopatts (Hamburg, Germany) and the substrate 3-amino-9-ethylcarbazol Sigma (Deisenhofen, Germany) as an indicator system as described elsewhere. ${ }^{21}$ Normal colonic tissue and tissues from inflammatory bowel disease and colorectal tumours were obtained from the department of surgery at our university.

To investigate the cell surface expression of
ICAM-1 on colonic cancer cell lines, cells were detached from confluent cultures by $0.05 \%$ ethylenediaminetetraacetic acid in phosphate buffered saline, washed once with CMRL medium, resuspended in CMRL medium supplemented with $10 \%$ basal medium supplement, and adjusted to $10^{5}$ cells per ml medium, as described elsewhere. ${ }^{20}$ CMRL medium (200 $\mu \mathrm{l})$, containing $2 \times 10^{4}$ cells per well, was plated on LAB-TEK no 4808 tissue culture slides from VWR Scientific (Naperville, USA) in the presence or absence of the tested cytokines, and cultured for 24 hours at $37^{\circ} \mathrm{C} / 5 \% \mathrm{CO}_{2}$ and high humidity. Cell surface expression was tested on unfixed cells and was performed according to the method described above.

RIBONUCLEIC ACID EXTRACTION AND NORTHERN BLOT ANALYSIS

Total ribonucleic acid was prepared from exponentially growing cells according to standard methods, ${ }^{22}$ assessed by measuring the absorbance at $260 \mathrm{~nm}$, separated on a formaldehyde containing agarose gel, and blotted to nylon filters.

Agarose gel electrophoresis, ribonucleic acid transfer, and hybridisation of blots were performed by standard techniques. ${ }^{23}$ The filters were probed with a $1.2 \mathrm{~kb}$ long Xba-1/Pst-1 restriction fragment of cDNA clone pICAM- $1,{ }^{24}$ kindly supplied by Dr B Seed (Boston, USA). The complementary DNA (cDNA) was labelled with $P^{32}$-dATP using the random priming method $^{25}$ and used at a concentration of $5 \times 10^{6}$ cpm of labelled cDNA per millilitre hybridisation solution. Hybridisation was performed at $65^{\circ} \mathrm{C}$ without formamide. The washing of the northern blots was carried out according to standard methods. ${ }^{23}$ The last washing step was performed in $0.3 \times \mathrm{SSC} / 0.1 \% \mathrm{SDS}$ for one hour at $65^{\circ} \mathrm{C}$. As previously described, the northern blot results were normalised by rehybridising the filters with a $\mathbf{P}^{32}$-labelled oligonucleotide (5'AACGATCAGAGTAGTGGTATTTCACC $3^{\prime}$ ) that corresponds with the 28 s ribosomal ribonucleic acid. ${ }^{26}$ This probe had been shown to be better than actin as a control for the amount and quality of total ribonucleic acid loaded. Kinase labelling, hybridisation, and washing of the blots was performed at $42^{\circ} \mathrm{C}$ according to standard procedures. ${ }^{23}$
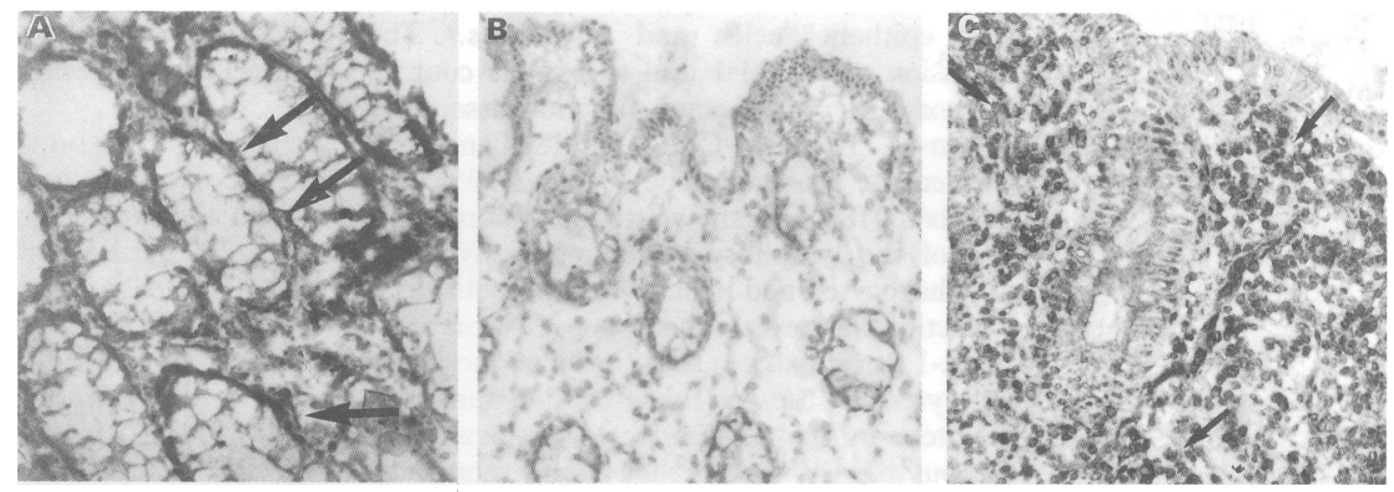

Figure 1: Expression of ICAM-1 on normal colon, carcinoma, and ulcerative colitis. Cryostat sections were stained by mAb 7F7. (A) Colonic cancer: immunostaining of tumour cells, most prominent at the basement membrane. (B) Normal colon: no ICAM-1 staining. (C) Ulcerative colitis: immunostaining of inflammatory phagocytic cells. 
A

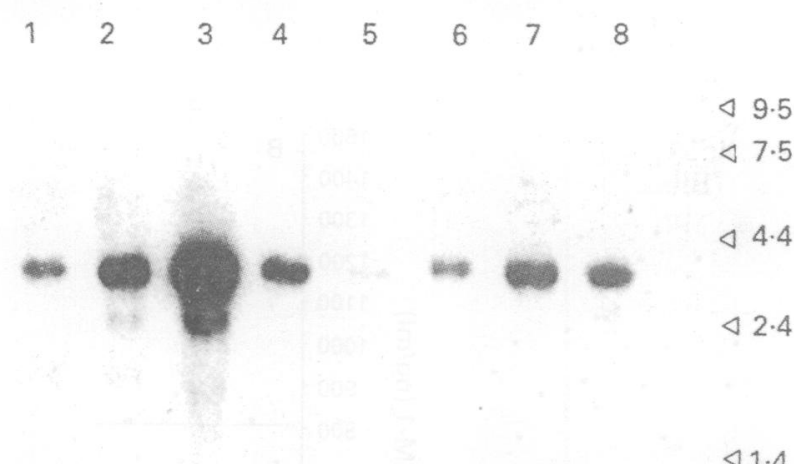

B

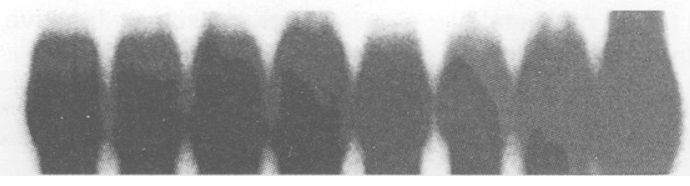

$\triangleleft 28 s$ rRNA

Figure 2: Northern blot analysis of total ribonucleic acid prepared from $\mathrm{HT}-29$ and $\mathrm{CaCo}-2$ cells after culturing for 24 hours in presence of IFN- $\gamma(100 \mathrm{U} / \mathrm{ml}), I L-1 \beta(100 \mathrm{U} / \mathrm{ml}), T N F-\alpha$ $(10 \mathrm{ng} / \mathrm{ml}$ ) or in absence of cytokines $(0)$. For each lane $20 \mathrm{\mu g}$ of total ribonucleic acid were

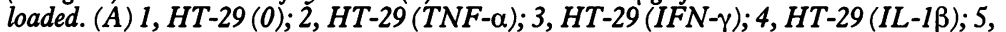

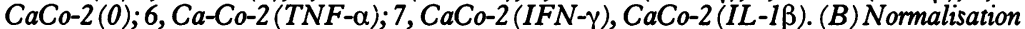
of the above shown northern blot using an oligonucleotide probe corresponding to $28 \mathrm{~s} r R N A$.

\section{SERUM SAMPLES}

Serum samples were obtained from healthy blood donors, patients with metastatic colorectal carcinoma without evidence of infection, and from patients with inflammatory bowel disease. The BEST index ${ }^{27}$ was used to evaluate activity and severity of Crohn's disease. It contains eight indices such as abdominal pain, number of liquid stools, score of general well being, and others. This index estimates predominantly patients' complaints (BEST $>150=$ active disease).

\section{Results}

DE NOVO EXPRESSION OF ICAM-1 IN COLONIC TISSUES

The expression of ICAM-1 was examined on colonic epithelial tissues, cryostat sections of normal colon (12 specimens), of ulcerative colitis (2) and Crohn's disease (2), and 16 tumour tissues of patients with primary colorectal carcinoma were stained with both antibodies, $\mathrm{mAb} 7 \mathrm{~F} 7$ and $\mathrm{mAb} 84 \mathrm{H} 10$. As shown in Figure $1 \mathrm{~A}$, a varying percentage $(10-70 \%)$ of colonic carcinoma cells showed a strong staining at the basement membrane site of the tumour cells with both antibodies. In contrast, normal colon tissue (beside a marginal staining of the blood vessel endothelium) did not react with antibodies directed against ICAM-1 (Fig 1C). In tissue specimens of chronic inflammatory bowel disease ICAM-1 expression (Fig 1B) was only detectable on the inflammatory mononuclear cells, but not close to epithelial cells.
DETECTION OF ICAM-1 MRNA IN COLON CARCINOMA CELL LINES

Total ribonucleic acid preparations from the two colonic tumour cell lines were subjected to northern blot analysis to investigate whether they expressed mRNA for ICAM-1. Figure 2A shows that ICAM-1 mRNA was abundantly expressed in untreated $\mathrm{HT}-29$ and $\mathrm{CaCo}-2$ colonic cancer cells.

To find out whether cytokine treatment would modulate ICAM-1 expression in HT-29 and $\mathrm{CaCo}-2$ cells, each of the cell lines was incubated for 24 hours in the absence or presence of IFN- $\gamma$ $(100 \mathrm{U} / \mathrm{ml}), \mathrm{IL}-1 \beta(100 \mathrm{U} / \mathrm{ml})$, or TNF- $\alpha(10 \mathrm{ng} /$ $\mathrm{ml})$. The highest abundance of $\mathrm{mRNA}$ for ICAM-1 was obtained with IFN- $\gamma$ in HT-29 cells. Figure 2A, representing one of three northern blot experiments performed, shows that a response to the cytokine treatment could be seen by the enhancement of ICAM-1 mRNA expression. In all ribonucleic acid preparations of ICAM-1 expressing cells, we always saw two hydridisation signals, a major signal at about $3.3 \mathrm{~kb}$ and a minor signal at about $2.4 \mathrm{~kb}$, indicating the expression of the two previously reported ICAM-1 mRNA species. Whenever the expression of the $3.3 \mathrm{~kb}$ mRNA was enhanced, the $2.4 \mathrm{~kb}$ mRNA was changed to the same extent.

DETECTION OF ICAM-1 ON THE CELL SURFACE OF COLONIC CARCINOMA CELL LINES

To examine if the expression of mRNA was followed by the expression of the ICAM-1 molecule on the cell surface, cytokine treated and untreated HT-29 and CaCo-2 cells were
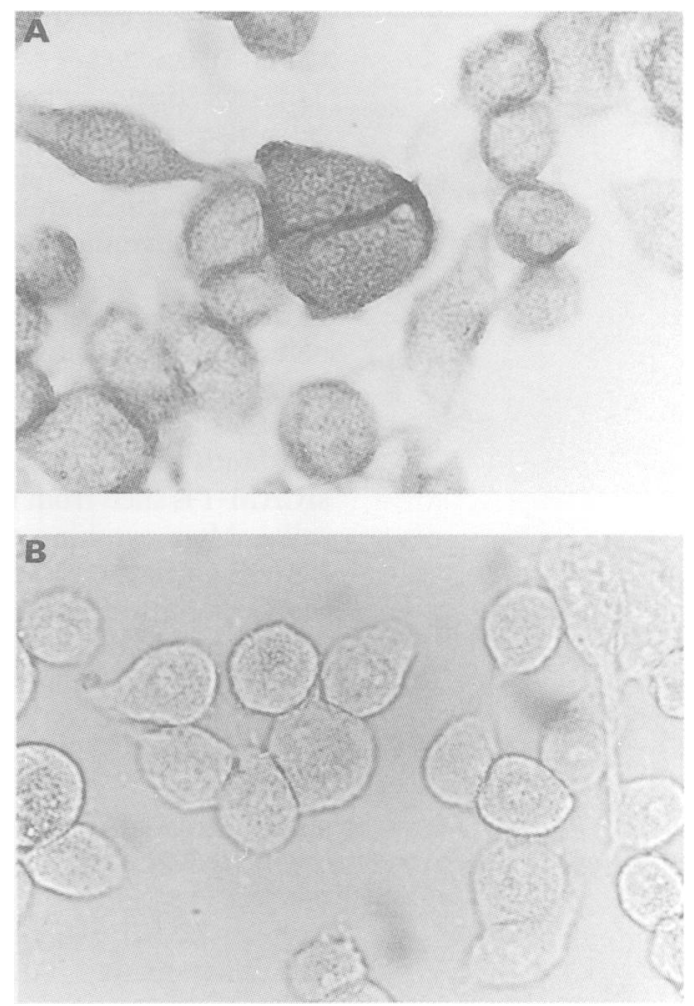

Figure 3: Expression of ICAM-1 on the surface of the colonic carcinoma cell line HT-29 shown by immunoperoxidase with $m A b$ 7F7. (A) Immunostaining with $m A b 7 F 7$;

(B) Immunostaining with $m A b R-24$ (negative control). 

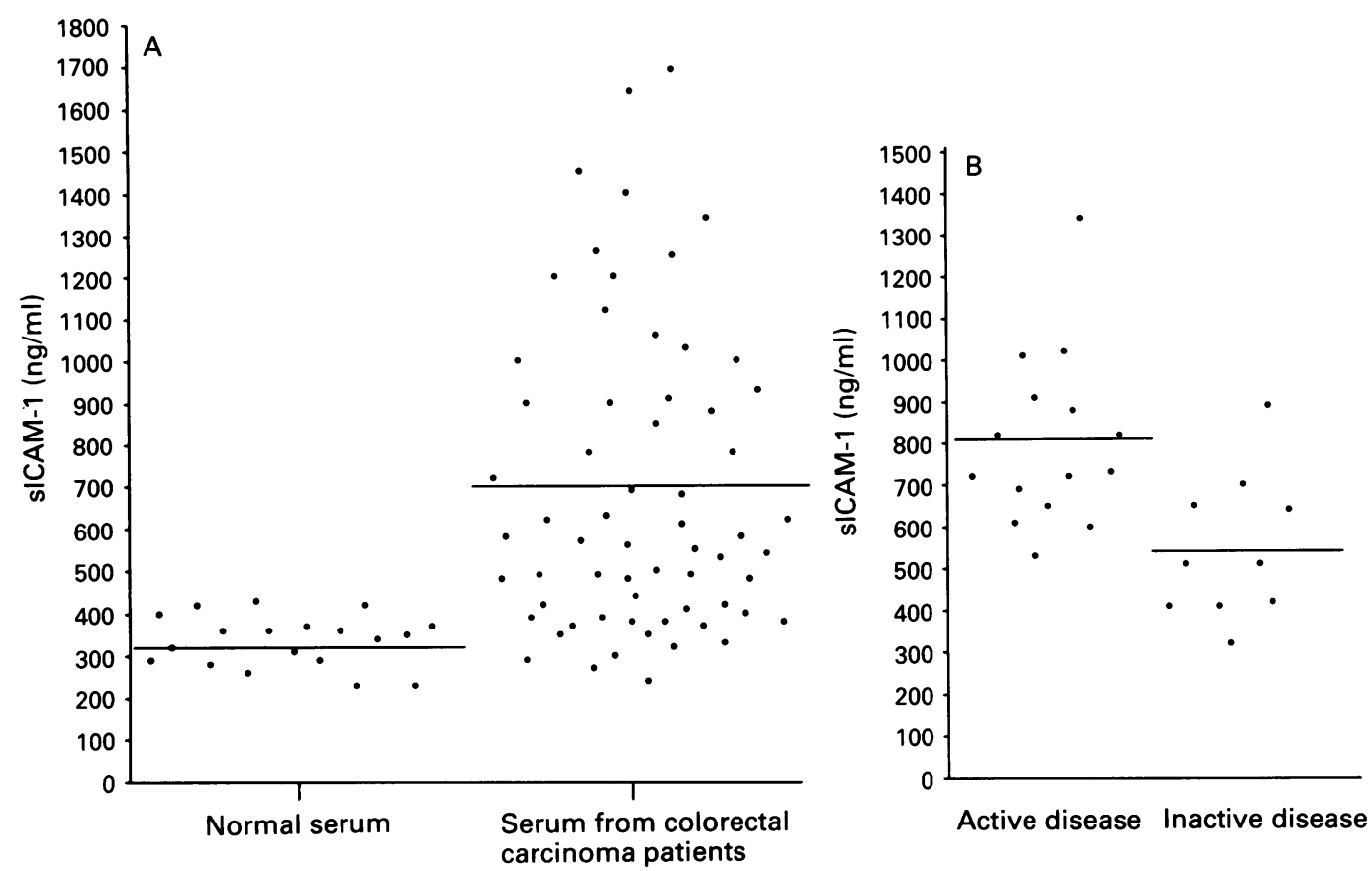

Figure 4: (A) Enhanced sICAM-1 serum concentrations detected in serum samples of patients with colorectal carcinomas compared with healthy blood donors; $(B)$ sICAM-1 in serum samples of patients with active and inactive Crohn's disease.

assayed with two different monoclonal antibodies directed against ICAM-1 (mAb 7F7 and $\mathrm{mAb} 84 \mathrm{H10}$ ). Figure 3 shows the immunostaining of HT-29 cells, after incubation with IFN- $\gamma$, with mAb 7F7. IFN- $\gamma$ and TNF- $\alpha$ induced enhanced ICAM-1 cell surface expression in HT-29 cells, while IFN- $\gamma$ and IL- $1 \beta$ enhanced ICAM-1 expression on $\mathrm{CaCo}-2$ cells.

\section{DETECTION OF SICAM-1 SHEDDED BY COLONIC CARCINOMA CELLS}

To investigate whether colonic carcinoma cells also shed the recently described soluble sICAM-1, culture supernatants were collected from confluently growing colonic tumour cell lines after five days of culture and assessed in duplicate in an ICAM-1 specific 'sandwich' ELISA. The comparative amounts of sICAM-1 determined from undiluted cell culture supernatants were $8.5 \mathrm{ng} / \mathrm{ml}$ for HT-29 cells and 13.5 for $\mathrm{CaCo}-2$ cells. The medium control was constantly negative for sICAM-1. Therefore sICAM-1 is shed from both, HT-29 and Ca-Co-2 cells. After cytokine treatment of HT-29 and CaCo- 2 cells, the values of sICAM-1 in some of the cell culture supernatants were raised for TNF- $\alpha$ twofold, for IFN- $\gamma$ fourfold in HT-29 cells, for IFN- $\gamma$ and IL- $1 \beta$ about twofold in CaCo-2 cells.

SICAM-1 IN SERUM SAMPLES FROM PATIENTS WITH COLONIC CARCINOMA AND INFLAMMATORY BOWEL DISEASE

To see whether patients with colonic carcinoma and inflammatory bowel disease show raised serum concentrations of sICAM-1, we compared the content of sICAM-1 in their serum samples with the sICAM-1 concentrations in samples of 19 healthy blood donors. Figure 4A shows that
sICAM-1 was present in the normal serum samples at an average of $334 \mathrm{ng} / \mathrm{ml}$, whereas the samples of colonic carcinoma patients contained sICAM- 1 at an average of $684 \mathrm{ng} / \mathrm{ml}$. In a MannWhitney-White analysis, these differences were shown to be highly statistically significant with $0.001<\mathrm{p}<0.0001$ at confidence intervals of $95 \%$. Some of the patients' samples showed extremely high sICAM-1 concentrations with up to $1 \cdot 700$ $\mathrm{ng} / \mathrm{ml}$ while only few did not differ from the control group. We also saw a significantly increased concentration $0.01<\mathrm{p}<0.001$ of sICAM-1 in the serum samples of 15 patients with active Crohn's disease (average $804 \mathrm{ng} / \mathrm{ml}$ ) compared with 10 patients with inactive disease (average $546 \mathrm{ng} / \mathrm{nl}$ ) (see Fig 4B). Five patients with active ulcerative colitis also showed increased serum concentrations of sICAM (640 $\mathrm{ng} / \mathrm{ml}$ ).

\section{Discussion}

The data presented show that colonic carcinoma cells express ICAM-1 molecules on their cell surface in contrast with normal colonic epithelium. In a previous report on a de novo expression of ICAM-1 by mucosal mononuclear phagocytes in inflammatory bowel disease, ${ }^{4}$ the percentage of mononuclear phagocytes was increased from $7 \%$ in controls to $70 \%$ in ulcerative colitis and to $45 \%$ in Crohn's disease. These findings were confirmed in this study. According to the analysis of Maliza and our data, however, the source of soluble ICAM-1 seems to be different, in inflammatory bowel disease, the mononuclear phagocytes and in colonic cancer, the tumour cells. The de novo expression of ICAM-1 in phagocytes of the colonic mucosa and the raised soluble ICAM-1 in active Crohn's disease and ulcerative colitis shown here are consistent with a condition of immunological 
activation induced by the local release of proinflammatory cytokines. Therefore, it may be of value to include the value of soluble ICAM-1 in the index of inflammatory activity in the clinical assessment and progression of inflammatory bowel disease. ${ }^{28} \mathrm{~A}$ study is underway that includes a large number of patients and their specific clinical and laboratory findings.

For the same reason we feel that it is important to determine ICAM-1 expression in tissues and serum samples of patients with colonic cancer, because ICAM-1 expression on melanoma was shown to be an important pathophysiological parameter. Patients whose primary tumours express abundant ICAM-1 have an increased risk of metastasis. ${ }^{1016} \mathrm{It}$ is therefore tempting to speculate whether the expression of ICAM-1 on colonic and pancreatic carcinoma cells ${ }^{13}$ may contribute, in an as yet unknown way, to the aggressive potential of colonic cancer cells. In the two colonic tumour cell lines cytokine treatment resulted in an induction or enhancement of ICAM-1 expression on the cell surface, but also increased the shedding of sICAM-1. In agreement with the findings in melanoma, the shedding of sICAM-1 could be a mechanism for colonic tumour cells to evade from lymphocyte mediated cytolysis. ${ }^{29}$ Therefore the relation between the ICAM-1 expression and the clinical course seems to be of diagnostic interest for colonic carcinoma. In conclusion it is justified to examine ICAM-1 expression as a potential prognostic risk factor for colonic carcinoma.

This study was supported by SFB 302 C 40 and the Naturwissenschaftlich-Medizinisches Forschungszentrum Mainz. WD is a
recipient of professorship of the Stifterverband für die Deutsche recipient of professorship of the Stifterverband für die Deutsche
Wissenschaft. The authors are most grateful to Dr M P Dierich for Wissenschaft. The authors are most grateful to Dr M P Dierich for
supplying the antibody mAb7F7 and Dr B Seed for generously contributing his cDNA clone for ICAM-1.

1 Springer TA, Dustin ML, Kishimoto TK, Marlin SD. The lymphocyte function-associated LFA-1, CD2, and LFA-3 molecules: cell adhesion receptors of the immune system. Annu Rev Immunol 1987; 5: 223-52.

2 Diamond MS, Staunton DE, Marlin SD, Springer TA Binding of the Integrin Mac-1 (CD11b/CD18) to the third immunoglobulin-like domain of ICAM-1 (CD54) and its regulation by glycosylation. Cell 1991; 65: 961-71.

3 Rothlein R, Czajkowski M, O'Neill MM, Marlin SD, Mainolf E, Merluzzi VJ. Induction of intercellular adhesion molecule-1 on primary and continuous cell lines by proinflammatory cytokines. F Immunol 1988; 141: 1665-9.

4 Malizia G, Calabrese A, Cottone M, Raimondo M, Trejdosiewicz LK, Smart CJ, et al. Expressions of leukocyte adhesion molecules by mucosal mononuclear phagocytes in inflammatory bowel disease. Gastroenterology 1991; 100 150-9. 5 Adams DH, Shaw J, Hubscher SG, Rothlein R, Neuberger
JM. Intercellular adhesion molecule-1 on liver allografts during rejection. Lancet 1989 ; ii: $1122-4$

6 Maio M, Pinto A, Carbone A, Zagonel V, Gloghini A, Marotta G, et al. Differential expression of CD54/intercellula adhesion molecule-1 in myeloid leukemias and in

7 Groliferative disorders. Blood 1990; 76: 783-90. Moulton TA, et al. Expression and modulation by cytokines of the intercellular adhesion molecule-1 (ICAM-1) in human central nervous system tumor cell cultures. Int $\mathcal{F}$ Cancer 1990; 46: 1041-7.

8 Taylor RS, Griffiths CE, Brown MD, Swanson NA, Nickoloff, BJ. Constitutive absence and interferon- $\gamma-$ induced expression of adhesion molecules in basal cell carcinoma. F Am Acad Dermatol 1990; 22: 721-6.

9 Barker JN, Allen MH, MacDonald DM. Distribution of intercellular adhesion molecule-1 (ICAM-1) and lymphocytefunction-associated antigen (LFA-1) in epidermal tumors. Clin Exp Dermatol 1990; 15: 331-4.

10 Johnson JP, Stade BG, Holzmann B, Schwaeble W, Riethmuiller, G. De novo expression of intercellular Riethmüller, G. De novo expression of intercellular adhesion molecule-1 in melanoma correlates with incr
risk of metastasis. Proc Natl Acad Sci 1989; 86: 641-4.

11 Tomita Y, Nishiyama T, Watanabe H, Fujiwara M, Sato S. Expression of intercellular adhesion molecule-1 (ICAM-1) on renal cell cancer: possible significance in host immune responses. Int $\mathcal{F}$ Cancer 1990; 46: 1001-6.

12 Koyoma S, Ebihara T, Fukao K. Expression of intercellular adhesion molecule 1 (ICAM-1) during the development of invasion and/or metastasis of gastric carcinoma. $\mathcal{F}$ Cancer Res Clin Oncol 1992; 118: 609-14.

13 Schwaeble W, Kerlin M, Meyer zum Büschenfelde K-H, Dippold W. De novo expression of intercellular-adhesion molecule 1 (ICAM-1, CD54) in pancreas cancer.Int $f$ Cancer 1993; 53: 328-33.

14 Vogetseder W, Feichtinger H, Schulz TF, Schwaeble W, Tabaczewski $\mathrm{P}$, Mitterer M, et al. Expression of 7F7antigen, a human adhesion molecule identical to antigen, a human adhesion molecule identical to
intercellular adhesion molecule-1 (ICAM-1) in human intercellular adhesion molecule-1 (ICAM-1) in human
carcinomas and their stromal fibroblasts. Int $\mathcal{F}$ Cancer 1989; 43: 768-73,

15 Rothlein R, Mainolfi EA, Czajkowski M, Marlin SD. A form of circulating ICAM-1 in human serum. F Immunol 1991; 147: 3788-93.

16 Altomonte M, Carbone A, Bertola G, Golombatti A, Ferrone $\mathrm{S}$, Maio. Functional role of cell adhesion molecules in the [Abstract]. Proc Am Assoc Cancer Res 1992; 33: 297.

17 Wawrky SO, Novotny JR, Wicks IP, Wilkinson D, Maher D, Salvaris E, et al. The role of LFA-1/ICAM-1 interaction in human leukocyte homing and adhesion. Immunol Rev 1989; 108: 135-61.

18 Möst J, Schwaeble W, Drach J, Sommerauer A, Dierich MP. Regulation of the expression of intercellular adhesion molecule-1 (ICAM-1) on human monocytes and monocytic tumor cell lines. F Immunol 1992; 148: 1635-42.

19 Dippold W, Lloyd KO, Li LTC, Ikeda H, Oettgen HF, Old LJ. Cell surface antigens of human malignant melanoma: definition of six antigenic systems with monoclonal antibodies. Proc Natl Acad Sci USA 1980; 77: 6114-8.

20 Dippold W, Klingel R, Kerlin M, Schwaeble W, Meyer zum Büschenfelde K-H. Stimulation of pancreas and gastric carcinoma cell growth by interleukin 3 and granulocytemacrophage colony-stimulating factor. Gastroenterology macrophage colon

21 1991; 100: 1338-44. K-H. Immunohistochemical localization of ganglioside GD3 K-H. Immunohistochemical localization of ganglioside GD3 in human malignant melanoma, epithelial

22 Chirgwin JM, Przybyla AE, MacDonald RJ, Rutter WJ. Isolation of biologically active ribonucleic acid from sources enriched in ribonuclease. Biochemistry 1979; 18: 5294-9.

23 Maniatis T, Frisch EF, Sambrook J. Molecular cloning. A laboratory manual. New York: Cold Spring Harbor Laboratory, Cold Spring Harbor Press, 1989.

24 Simmons D, Makoba MW, Seed B. ICAM-1, an adhesion ligand of LFA-1, is homologous to the neural adhesion molecule NCAM Nature 1988; 331:624-7.

25 Feinberg AP, Vogelstein B. A technique for radiolabeling DNA restriction endonuclease fragments to high specific activity. Anal Biochem 1983;132: 6-13.

26 Barbu, Dautry F. Northern blot normalization with a $28 \mathrm{~S}$ rRNA oligonucleotide probe. Nucleic Acid Res 1989; 17: rRNA.

27 Best WR, Becktel JM, Singleton JW, Kern F. Development of a Crohn's disease activity index. Gastroenterology 1976; 70: 439-44.

28 Seth R, Raymond FD, Makgoba MW. Circulating ICAM-1 isoforms: diagnostic prospects for inflammatory and immune disorders. Lancet 1991; 338: 83-4.

29 Vanky F, Wang P, Patarroyo M, Klein E. Expression of the adhesion molecule ICAM-1 and major histocompatibility complex class I antigens on tumor cells is required for their interaction with autologous lymphocytes in vitro. Cancer Immunol Immunother 1990; 31: 19-27. 